\title{
Ceramic Injection Moulding of engineered glass-ceramics: Boosting the Rare-Earth free photoluminescence
}

\author{
E. Enríquez ${ }^{* 1}$, C. Berges 2 , V. Fuertes ${ }^{1}$, A. Gallego ${ }^{2}$, J. A. Naranjo2, G. Herranz², J. F. \\ Fernández ${ }^{1}$ \\ 1Dept. Electrocerámica, Instituto de Cerámica y Vidrio, CSIC, Kelsen 5, 28049, Madrid, Spain. \\ 2 ETSII-INEI. Universidad de Castilla La Mancha. Avda Camilo Jose Cela s/n. 13071, Ciudad Real. Spain
}

\begin{abstract}
The obtaining of dense ceramic pieces with versatility of size and shape is a much sought-after objective. Powder Injection Moulding (PIM) and Ceramic Injection Moulding (CIM), in particular, is a well-known technology that allows preparing this kind of complex parts with great variety of materials and at large production volume in a cost-efficient way. Usually, this process provides structural materials for mechanical and conforming purposes, but very few works have focused on manufacture functional porcelains. In this work, CIM method is used to process rare-earth free glass-ceramics with photoluminescent properties. The CIM parameters are optimized to obtain dense ceramic parts based on $\mathrm{Na}$-rich plagioclase previously designed. The CIM processed samples show a higher structural disorder as studied by XRD and Raman spectroscopy and variations of the micro-nanostructure, in comparison with conventional ceramic processed samples. Photoluminescent emission studies show an increase of almost one order of magnitude on the UV-blue emission, due to the rise of the structural defect population generated by the CIM process. The CIM process, thus, provides results that boosted the use of rare-earth free materials for luminescence application having complex shapes.
\end{abstract}

Keywords: Glass-ceramic; photoluminescence; ceramic injection moulding; rare-earth free

\section{Introduction}

Glass-ceramic materials have excellent properties (good mechanical properties, chemically inert, low porosity, low thermal conductivity, etc.) that make them good candidates for countless applications, such as electronics, dental issues, insulators, luminescent matrix, etc. Usually, the

\footnotetext{
"Corresponding author. Tlf:+34 91735 58 40; Ext 1076. Fax: +34 91735 58 43. E-mail address: esther@icv.csic.es (E. Enríquez)
} 
most common procedures to manufacture these porcelain materials are by pressing or slip continuous increase of nanotechnologies and nanoscience in the last decades, make it necessary the development of small pieces with complex geometries having functional properties which may be integrated in different kind of devices.

Powder Injection Moulding (PIM) is an advanced manufacturing technology widely implemented in industry which combines the conventional Powder Metallurgy processes with the polymer injection. Employing this procedure, it is possible to prepare a great variety of objects with the desired shapes and sizes based on different powder materials comprising metals (Metal Injection Moulding or MIM) and ceramics families (Ceramic Injection Moulding or CIM). The process comprises multiple stages, starting with mixing the selected powder and binder system, usually multicomponent based on thermoplastic polymers, to produce the mixtures, called feedstocks, with adequate viscosity. Then, injection moulding machine is fed with the optimized feedstock pellets, which are heated and pressured, so the mould can be filled in an adequate way. After cooling, the component with the desired geometry is ejected and this injection cycle is repeated. Debinding of the resulting green parts is performed by a solvent, thermal or catalytic process (depending on the binder used) and a residual binder amount is left for holding powder particles. Brown parts are finally sintered upon temperature leading to high-densified components with its corresponding dimensional shrinkage. The preferred powder properties typically include a particle size lower than $25 \mu \mathrm{m}$, a broad particle size distribution and a spherical shape; while feedstock viscosity is required to be lower than $1000 \mathrm{~Pa} \cdot \mathrm{s}$ during the injection process, which usually occurs at shear rates in the range of 100 and $1000 \mathrm{~s}^{-1}[2,3]$.

Traditionally, the most common ceramic pieces produced by CIM have been structural materials, that is, pieces fabricated for mechanical and conforming purposes, such as aerospace systems, metal machining or automotive engines [1]. In the last ten years, the aesthetical market has significantly grown, leading for example to luxury coloured-zirconia watches or car interiors. Moreover, the increasing demand on functional materials enabled the introduction of $\mathrm{CIM}$ components into a new range of industrial applications related to car emissions reduction, longer batteries power, medical products and electronic industry [6]. However, these examples in which CIM provides an improvement in the functional properties of ceramic materials are usually restricted to alumina and zirconia feedstocks, being less common in the field of functional porcelains. 
Therefore, obtaining a high dense ceramic component by means of a CIM procedure, which is complex-shaped and preserves or, even more, boosts the basic and functional properties, is a much desired challenge.

Recently, engineered feldspars in form of glass-ceramics based on albite type structure have been obtained with interested optical properties $[7,8]$. These materials are free of rare-earth and possess high luminescence due to the structural defects produced by the order/disorder of its structure. The albite structure consists of rings of four tetrahedra, where each tetrahedron is centered by a $\mathrm{Si}^{4+}$ or an $\mathrm{Al}^{3+}$ cation with a $\mathrm{Si}^{4+} / \mathrm{Al}^{3+}$ ratio of $3: 1$, and the oxygen atoms are located at the corners linking two tetrahedra. Albite has four symmetrically nonequivalent sites designated as $\mathrm{T} 1(0), \mathrm{T} 1(\mathrm{~m}), \mathrm{T} 2(0)$, and $\mathrm{T} 2(\mathrm{~m})$. In the most ordered state (low albite), $\mathrm{Al}^{3+}$ cations are placed in $\mathrm{T} 1(0)$ positions but, when disorder increases, they migrate to the other three positions. For intermediate plagioclases (albite-anorthite solid solutions), some $\mathrm{Na}^{+}$cations are replaced for $\mathrm{Ca}^{2+}$, which modifies the Si-Al ordering and favors the formation of defects $[9,10]$. These structural defects can be modified by the crystallization degree and sintering process [8].

In this work, this functional glass-ceramic based on sodium feldspar (albite) is used to obtain dense ceramic parts by CIM with the aim of boosting their interested optical properties. An important step in the CIM process is to condition the ceramic powder, since the particle size distribution, specific surface area and purity of powder are essential parameters to produce a feedstock with the adequate viscosity. The optimal ceramic powder content and binder composition of the feedstock is determined according to the torque evolution during the mixing step and the rheological study of the different feedstocks prepared. Debinding process is optimized to achieve defect-free brown parts to be subsequently sintered. Physical properties of the final sintered parts are measured by apparent density. The evaluation of the mechanical properties, in terms of bending tests, of the final parts sintered at different temperatures are used to select the optimal sintering temperature of CIM process. Finally, structural, microstructural and functional properties are analyzed, specially photoluminescence emission, by means of XRD, FESEM, Confocal Raman spectroscopy and photoluminescence, in order to determine the effect of CIM process in comparison with a conventional ceramic route.

\section{Experimental procedure}

\subsection{Materials}

The ceramic base powders of the feedstock was provided by Vidres S.A. and it was a glassceramic material developed with conventional ceramic procedures in previous works, based on Na-rich plagioclase feldspar compositions that upon sintering develop a high crystalline glass- 
ceramic $(94 \%)[11,12]$. This new glass-ceramic possesses a dual micro-nanostructure formed by microcrystals of $\sim 6 \mu \mathrm{m}$ surrounded by nanoregions of the same material. The glass-ceramic material was pre-treated at $700^{\circ} \mathrm{C}-1 \mathrm{~h}$, removing the crystal $\mathrm{OH}^{-}$of kaolin to obtain a pre-ceramic which could be mixed with the polymer to form the feedstock. This pre-treatment will control the devitrification process, influencing on the later material nucleation and crystallization. The particle size of the powder before and after the pre-treatment was $d_{50}=9.60 \mu \mathrm{m}$ and $d_{50}=9.34 \mu \mathrm{m}$, respectively, that is, they do not modify and are adequate for the CIM procedure.

The multicomponent binder employed to produce the feedstocks, containing a combination of thermoplastics polymers, waxes and surfactants in the adequate ratio, was designed according to previous studies in the group [13]. High-density polyethylene (HDPE) was supplied by Chemieuro S.L., while paraffin wax (PW) and stearic acid (SA) were supplied by Panreac Applichem. The balanced mixture of powder and binder leads to an optimal CIM feedstock with appropriate viscosity properties for the injection process. Otherwise, excess binder produces inhomogeneity in the moulded component and collapsing during the debinding stage, since the particles are not close enough to each other; whereas too little binder leads to a high viscosity situation in which material is difficult to mould, exceeding the critical ceramic loading. Feedstocks are typically formulated slightly below the critical volume powder content, CVPC, (the optimal powder loading is set between 2 and $5 \%$ less) to ensure successful injection, debinding and sintering processes [3].

For study purposes, the sample obtained by CIM technology from the feedstock was compared to the precursor glass-ceramic, the Na-rich feldspar (albite), obtained by conventional ceramic powder process $(\mathrm{CP})$, uniaxial pressed at $400 \mathrm{~kg} / \mathrm{cm}^{2}$ and fast-sintered at $1200^{\circ} \mathrm{C}[7-8]$.

\subsection{Processing and characterization}

The absolute density of the powder raw materials was characterized by a Helio Accupyc II 1340 pycnometer that provides a value of $2.67 \mathrm{~g} / \mathrm{cm}^{3}$. The particle size distribution is determined by laser particle analyser Microtrac Snyc. Thus, granulometry results of the ceramic powder is $d_{10}=$ $1.63 \mu \mathrm{m}, d_{50}=9.34 \mu \mathrm{m}$ and $d_{90}=35.43 \mu \mathrm{m}$ (see figure $S_{1}$ of supporting information), and The densities of the binder components were $\rho=0.94 \mathrm{~g} / \mathrm{cm}^{3}$ for HDPE, $\rho=0.91 \mathrm{~g} / \mathrm{cm}^{3}$ for paraffin wax and $\rho=1.00 \mathrm{~g} / \mathrm{cm}^{3}$ for stearic acid. In this way, different powder/binder mixtures with ceramic loadings in the range of $45-70$ vol.\% were accomplished, keeping a volumen ratio in the binder of 30:65:5 (HDPE:PW:SA). The mixing process was carried out in a ThermoHaake double 
rotor mixer (Haake Rheocord 252p model) set at $30 \mathrm{rpm}$ and $160^{\circ} \mathrm{C}$. The feedstocks obtained were pelletized in a Restch SM-100 mill. Rheological studies were performed in a Dynisco LCR 7000 series capillary rheometer. Experiments were carried out varying the temperature from $150^{\circ} \mathrm{C}$ to $170^{\circ} \mathrm{C}$, at shear rates selected between 10 and $10000 \mathrm{~s}^{-1}$. A die having $\mathrm{L} / \mathrm{D}=30$ and a 0 1400 bar pressure sensor were used. Rabinowitch correction was applied to the data in order to estimate the real wall shear rate during the experiments [14]. The injection stage of the selected feedstock was performed in a high-pressure equipment Arburg 270 s machine varying the experimental conditions of temperature in the range of $150-180^{\circ} \mathrm{C}$ and flow in the range of $20-25$ $\mathrm{cm}^{3} / \mathrm{s}$.

The thermal debinding cycles were set in a Hobersal furnace (12PR450/SCH PAD P) in the temperature range from $25^{\circ} \mathrm{C}$ to $440^{\circ} \mathrm{C}$ under flowing air. Several heating cycle were studied: ramp at $3^{\circ} \mathrm{C} / \mathrm{min}$ to $120^{\circ} \mathrm{C}$ (hold $1 \mathrm{~h}$ ), ramp at $1^{\circ} \mathrm{C} / \mathrm{min}$ to $380^{\circ} \mathrm{C}$ (hold $2 \mathrm{~h}$ ) and ramp at $1{ }^{\circ} \mathrm{C} / \mathrm{min}$ to $440^{\circ} \mathrm{C}$ (hold $1 \mathrm{~h}$ ), followed by a free cooling rate at the furnace. Brown parts were sintered in a tubular furnace Hobersal furnace (ST 186030) under air atmosphere. Heating rates were $5{ }^{\circ} \mathrm{C} / \mathrm{min}$ and maximum sintering temperatures were selected in the range between $1100^{\circ} \mathrm{C}$ and $1250^{\circ} \mathrm{C}$, which was maintained for $30 \mathrm{~min}$ and then were cooled down slowly inside the furnace. Mechanical properties were measured by a 4-points bending tests (modulus of rupture, MOR) which were performed in a SHIMADZU equipment (Autograph AG-X $50 \mathrm{KN}$ ) applying $1 \mathrm{~mm} / \mathrm{min}$ speed to the samples. Each result is the average of at least 5 experiments.

Porosity was measured on polished surfaces by means of optical microscopy and with Leica Qwin Image software. Structural characterization was carried out by means of XRD using a diffractometer Bruker D8 Advance with Cu Ka radiation, $40 \mathrm{kV}$ and $40 \mathrm{~mA}$ in order to identify the crystalline phases formed, which were identified by comparison with the corresponding JCPDS cards; and by means of Raman spectroscopy, using a Confocal Raman Microscope (Witec ALPHA 300RA) with a $\mathrm{Nd}$ :YAG laser light source $(532 \mathrm{~nm})$ in p-polarization. Optical resolution of this confocal microscope is, approximately, $250 \mathrm{~nm}$ and $700 \mathrm{~nm}$ in the longitudinal and transversal directions, respectively. The reflected laser light at each point was collected using a multimode optical fibre of $25 \mu \mathrm{m}$ in diameter by a very sensitive CCD detector which works at $-60^{\circ} \mathrm{C}$, cooling thermoelectrically with Peltier plates, and with a resolution of 1044x157 pixels. Measurements were performed using objectives of $100 x$ with a numerical aperture (NA) of 0.95 . The acquired spectra were analysed by using Witec Project 2.02 program and Witec Control Plus Software. 
Microstructural characterization was analyzed by means of Field Emission Scanning Electron Microscopy (FESEM), using a Hitachi S-4700 with polished samples chemically etched with 5 vol\% of $\mathrm{HF}$ to remove the glassy phase and reveal the micro-nanostructure.

The photoluminescence $(\mathrm{PL})$ measurements were carried out with a spectrofluorometer (Fluorolog®3, HORIBA Jobin Yvon) at room temperature. The luminescence intensity was measured over the wavelength 330-700 nm using a Xenon arc lamp as an excitation source (lexc 1/4 $380 \mathrm{~nm}$ ).

The deconvolution peaks of the PL and Raman measurements were determined by the $2^{\text {nd }}$ derivate of the experimental data using the Origin software and the derivate method used was Savitzky-Golay with a polynomial order of 2 . The peaks were filtered by height with a threshold of $20 \%$. The parameters obtained by the software were contrasted with the information in the literature, achieving an equilibrium between the physical meaning and the mathematical fitting. The goodness of the fit was $R^{2}=0.999$ in all cases.

\section{Results and discussion}

\subsection{Optimization of the ceramic feedstock}

The feedstocks preparation starts by mixing the glass-ceramic powder and the binder, gradually increasing the ceramic loading from 45 vol.\% up to 73 vol.\%. Torque evolution during mixing process is registered for each feedstock and steady state torque values after $60 \mathrm{~min}$ homogenization are shown in Figure $1 \mathrm{a}$. 

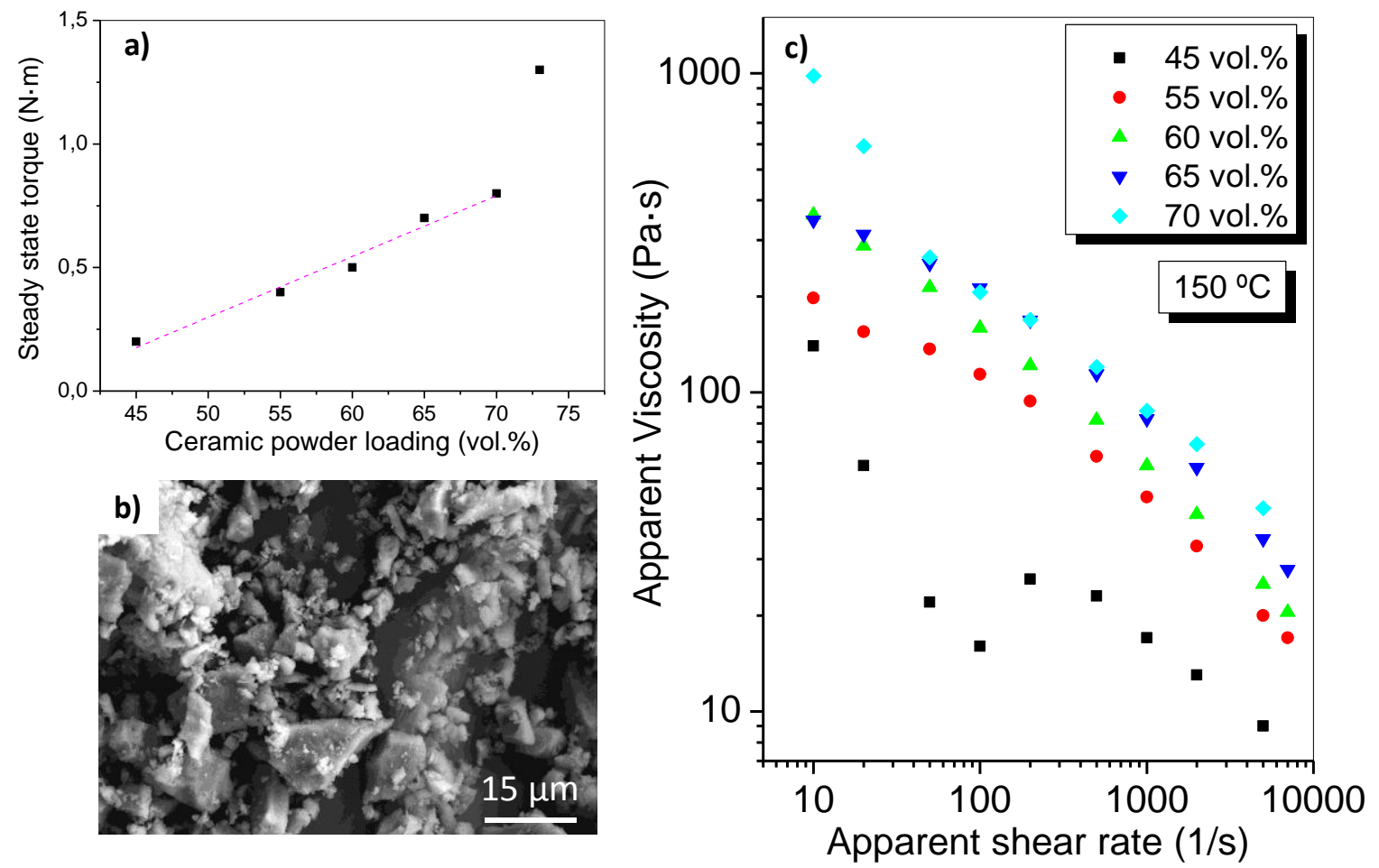

Figure 1. a) Steady state torque values for each ceramic loading of the feedstocks; b) FE-SEM micrograph of the glass-ceramic powder used as load; c) Apparent viscosity evolution under the shear rate increment for the different feedstocks (45-70vol. $\%$ ceramic loading) at $150^{\circ} \mathrm{C}$.

As it was expected, the increment of the ceramic loading in the mixtures leads to higher torque values, which also corresponds to higher viscosity values (figure 1c). It is worth noting that torque values show a non-linear increase above a ceramic loading of 70 vol.\%, as seen in figure 1a, which indicates that critical solid loading is reached, as it will be discussed later. Figure $1 \mathrm{~b}$ shows the FE-SEM micrograph of the glass-ceramic powder used as load, where the particle size distribution can be observed, which agrees with the data provide before by granulometry measurements, and an irregular morphology is determined.

The rheological behavior of the different mixtures is evaluated by measuring the apparent viscosity. Feedstocks with 73 vol.\% is not included in this study since it presented a too elevated viscosity at the lowest studied temperature $\left(150^{\circ} \mathrm{C}\right)$ and it was not possible to perform the experiment in the shear rate range of the equipment. Figure $1 \mathrm{c}$ shows the viscosity evolution at $150^{\circ} \mathrm{C}$ as an example, where it was confirmed that higher glass-ceramic powder loading corresponds to higher viscosity values. Besides, feedstocks present a pseudoplastic behavior, that is, viscosity values decrease when the shear rate is increased. In all cases, viscosity values were lower than $1000 \mathrm{~Pa} \cdot \mathrm{s}$ at the typical shear rate achieved during the injection process (between 100 and $1000 \mathrm{~s}^{-1}$ ). This fact indicates appropriate flow behavior, with the exception of 
feedstock with $45 \mathrm{vol} . \%$, which presents an anomalous behavior, showing a viscosity increase 


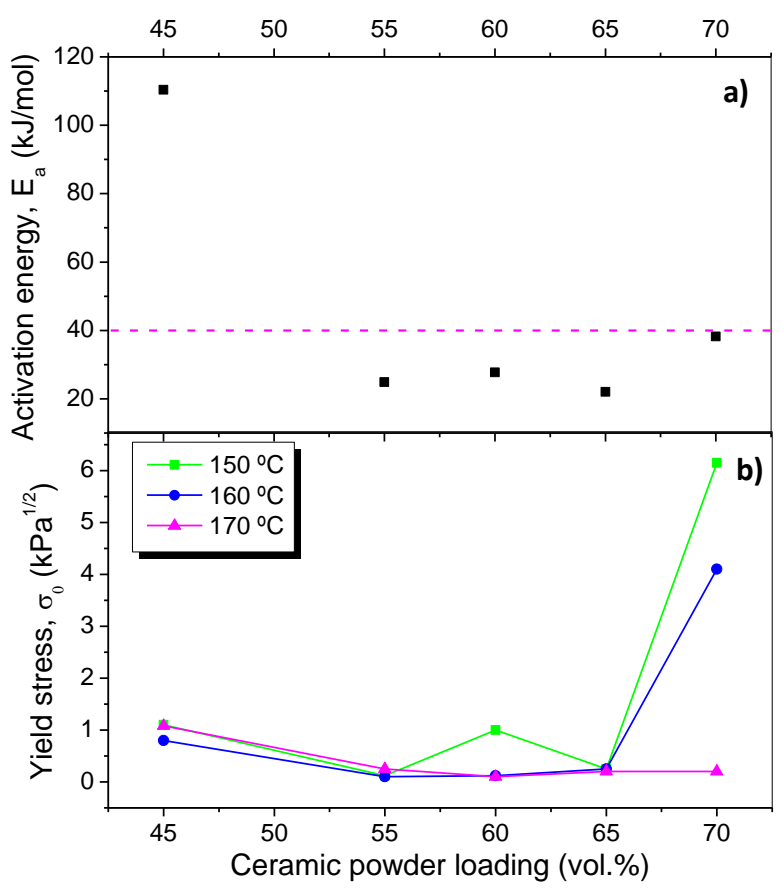

Figure 2. Rheological parameters calculated for the different feedstocks composition in the temperature range of $150-170^{\circ} \mathrm{C}$ : a) activation energy at $1000 \mathrm{~s}^{-1}$ shear rate and b) yield stress.

Finally, the Critical Volume Powder Content parameter (CVPC) is estimated according to Janardhana model [17] (see equation S4 of supporting information), and the results show that the critical powder content is $72 \mathrm{vol} . \%$, which is in accordance with the mixing behaviour observed during the feedstock preparation (Figure 1a and 1c). As commented above, for the correct feedstock design, reducing the powder content with respect to the CVPC is recommended to ensure adequate viscosity values during the injection process.

Therefore, regarding all the parameters studied, it can be concluded that the selected optimal powder content (the maximum value allowed is required to facilitate the sintering process) is 70 vol.\% of load, since it shows adequate pseudoplasticity, a reduced influence of temperature on viscosity, an acceptable yield stress values for the injection process at temperatures above $170^{\circ} \mathrm{C}$ and it is in the range predicted by the Janardhana model.

Once the ceramic load was chosen, green parts are successfully produced after the injection process of the $70 \mathrm{vol} \%$ feedstock using the high-pressure injection machine (see Figure 4). According the above results, a nozzle temperature of $170^{\circ} \mathrm{C}$ and a $25 \mathrm{~cm}^{3} / \mathrm{s}$ flow are set as experimental conditions to assure an optimal viscosity. The debinding conditions are optimized to achieve brown parts without any defects (cracks or bubbles) after the thermal decomposition of most of the binder. Finally, once high quality brown parts are accomplished, sintering process is 
optimized to manufacture high performance ceramic components (fully dense and good mechanical properties materials). The optimal sintering temperature, tested between $1100^{\circ} \mathrm{C}$ and $1250^{\circ} \mathrm{C}$, is selected considering the results regarding the apparent density and the bending strength. Figure 3 shows an increase of the apparent density and the bending strength, as the temperature reaches $1200^{\circ} \mathrm{C}$. Above this temperature, both parameters decrease again. Therefore, the sintering cycle adopted is $1200^{\circ} \mathrm{C}$ (hold $30 \mathrm{~min}$ ) at $2^{\circ} \mathrm{C} / \mathrm{min}$, leading to an apparent density of $2.60 \mathrm{~g} / \mathrm{cm}^{3}$ and mechanical properties of MOR $=88 \pm 8 \mathrm{MPa}$. In comparison with the glass-ceramic sintered by de ceramic process (CP) at the same sintering cycle $\left(\rho=2.7 \mathrm{~g} / \mathrm{cm}^{3}\right.$ and $\mathrm{MOR}=83 \mathrm{Mpa}$ ), the sample obtained by $\mathrm{CIM}$ presents a density $4 \%$ lower. Apparent density of both samples is very similar, which corroborate that the CIM method achieves densification degrees similar to the ceramic procedure. In addition, sample processed by CIM has slightly improved mechanical properties, achieving a MOR value $6 \%$ higher. Porosity of both samples were measured in order to compare the physical differences derived from the different preparation methods and to explain the similarity of density and mechanical properties. The pore total area and pore distribution shown differences between both samples (see table 1). The polymer burnt out during the debinding generates slightly more pores which are traduced in a lower density. However, the average pore diameter is similar for the two samples which preserve the mechanical properties. The difference in porosity can be clearer observed in figures $3 c-f$ which show the representative micrographs obtained by the optical profilemeter and the pores size distribution for each sample. CP sample (figure $3 c, d$ ) presents smaller pores than CIM sample (figure $3 e, f$ ), being the majority of particles between $0-10 \mu \mathrm{m}$ in diameter, with lower percentage between 10-20 $\mu \mathrm{m}$. However, in CIM sample there is larger accumulation of pores with diameters between $10-15 \mu \mathrm{m}$, even of $\sim 20-30 \mu \mathrm{m}$, as seen in the pores distribution (figure 3f). 

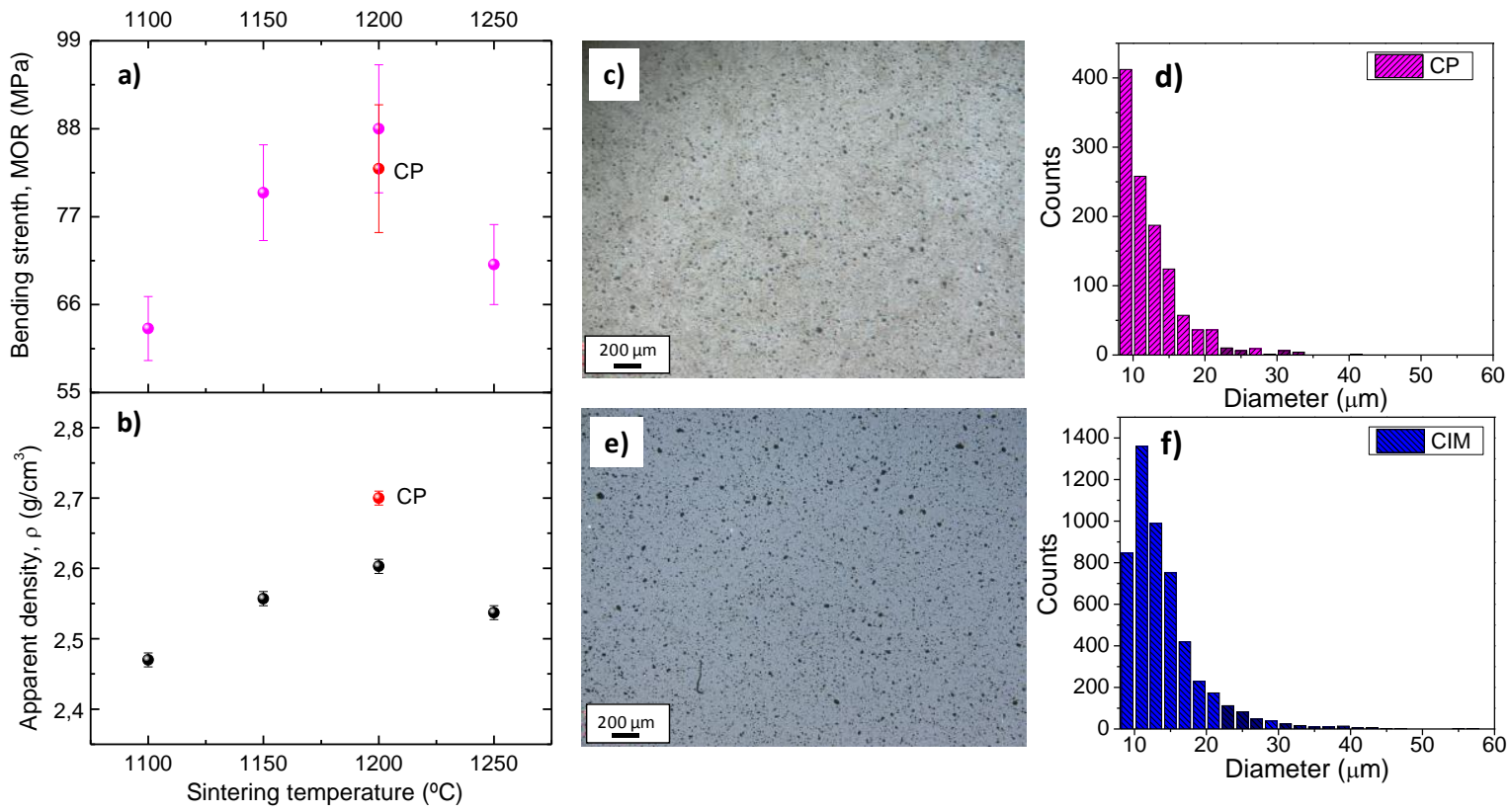

Figure 3: a) Apparent density and $\mathbf{b}$ ) bending strength (MOR) values at different sintering temperatures; Representative micrographs obtained by the optical microscopy and the pores size distribution for $\mathrm{c}, \mathrm{d}) \mathrm{CP}$ and $\mathrm{e}, \mathrm{f}) \mathrm{CIM}$ samples sintered at $1200^{\circ} \mathrm{C}$.

\begin{tabular}{ccc}
\hline Sample & Pore total area $(\%)$ & Average pore diameter $(\mu \mathrm{m})$ \\
\hline CIM & $13.23 \pm 0,01$ & $14.01 \pm 0,07$ \\
\hline CP & $4.12 \pm 0,01$ & $12,29 \pm 0,13$ \\
\hline
\end{tabular}

Table 1. Pore total area and average pore diameter of the prepared samples.

Figure 4 shows the green parts after the injection process, brown parts after the debinding stage, the final sintered parts by $\mathrm{CIM}$ and the sintered glass-ceramic obtained by $\mathrm{CP}$. The shrinkage occurring in the final ceramic parts processed by $\mathrm{CIM}$ is $11.8 \pm 0.7 \%$, while the shrinkage of the sintered ceramic by $\mathrm{CP}$ is $13.4 \pm 0.2 \%$. Therefore, the material shrinkage after sintering does not significantly differ between studied methods. 
Figure 4. From below to above: green, brown, sintered part of glass-ceramics processed by CIM and processed by $\mathrm{CP}$.

\subsection{Structural and Microstructural Characterization}

Figure 5 shows the XRD patterns corresponding to the crystalline phases which is quite similar for both samples: Na-rich feldspar (albite) (JCPDS card no. 01-083-1609) as the majority phase, and $\mathrm{ZrO}_{2}$ (JCPDS card no. 00-033-1483) and quartz (JCPDS card no. 00-013-0026) as secondary phases. However, CIM sample presents more defined diffraction peaks, with higher intensity, which indicates larger crystallinity due to the intermediate thermal treatment applied to the precursor, which has favored the devitrification process. 


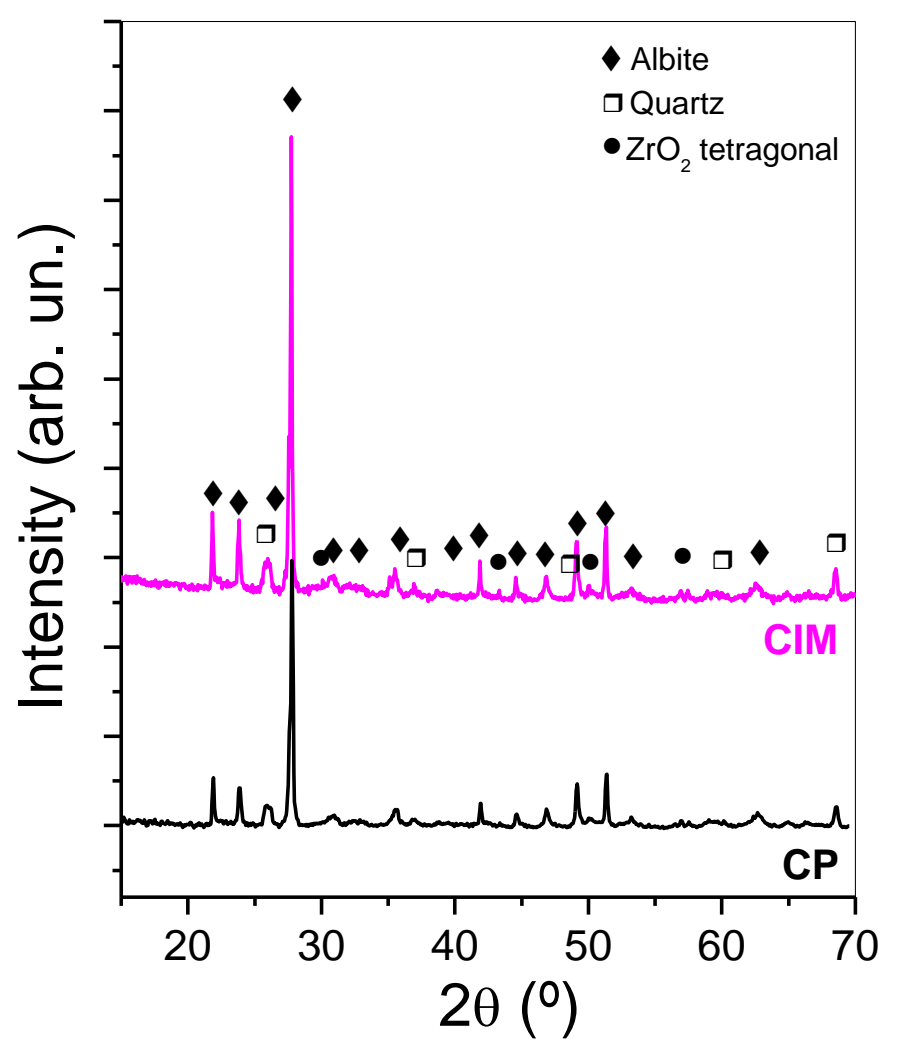

Figure 5: XRD patterns of the sample prepared by CIM and CP processes.

Figure 6 shows the FESEM micrographs of the $\mathrm{CP}$ (figures $6 \mathrm{a}$ and $6 \mathrm{~b}$ ) and of $\mathrm{CIM}$ (figures $6 \mathrm{c}$ and 6d) samples. CP sample shows feldspar elongated microcrystals of 2-10 $\mu \mathrm{m}$ in size and surrounded by the nanoregion formed of the same composition (figure $6 a, b$ ), as it was stated in a previous work [16]. At larger magnifications (figure 6b), it is possible to observe the nanoregions formed by nanoparticles of $\sim 40 \mathrm{~nm}$ in diameter. These nanoparticles possess a localized and incipient coalesce in form of sintering bottlenecks. Figure $6 \mathrm{c}$ and $6 \mathrm{~d}$ show the microstructures of sample prepared by CIM, where it is possible to observe that the feldspar microcrystals are bigger in size and having lower aspect ratio. This sample possesses larger areas having nanoregions that do not completely surrounded the microcrystals in the same degree as in the case of CP sample. Moreover, the nanoparticles of the nanoregions are $100 \mathrm{~nm}$ in diameter that are larger in size when compared with the CP sample. Moreover, nanoparticles at the nanoregions shown a higher degree of coalescence (figures $6 \mathrm{~d}$ ). 


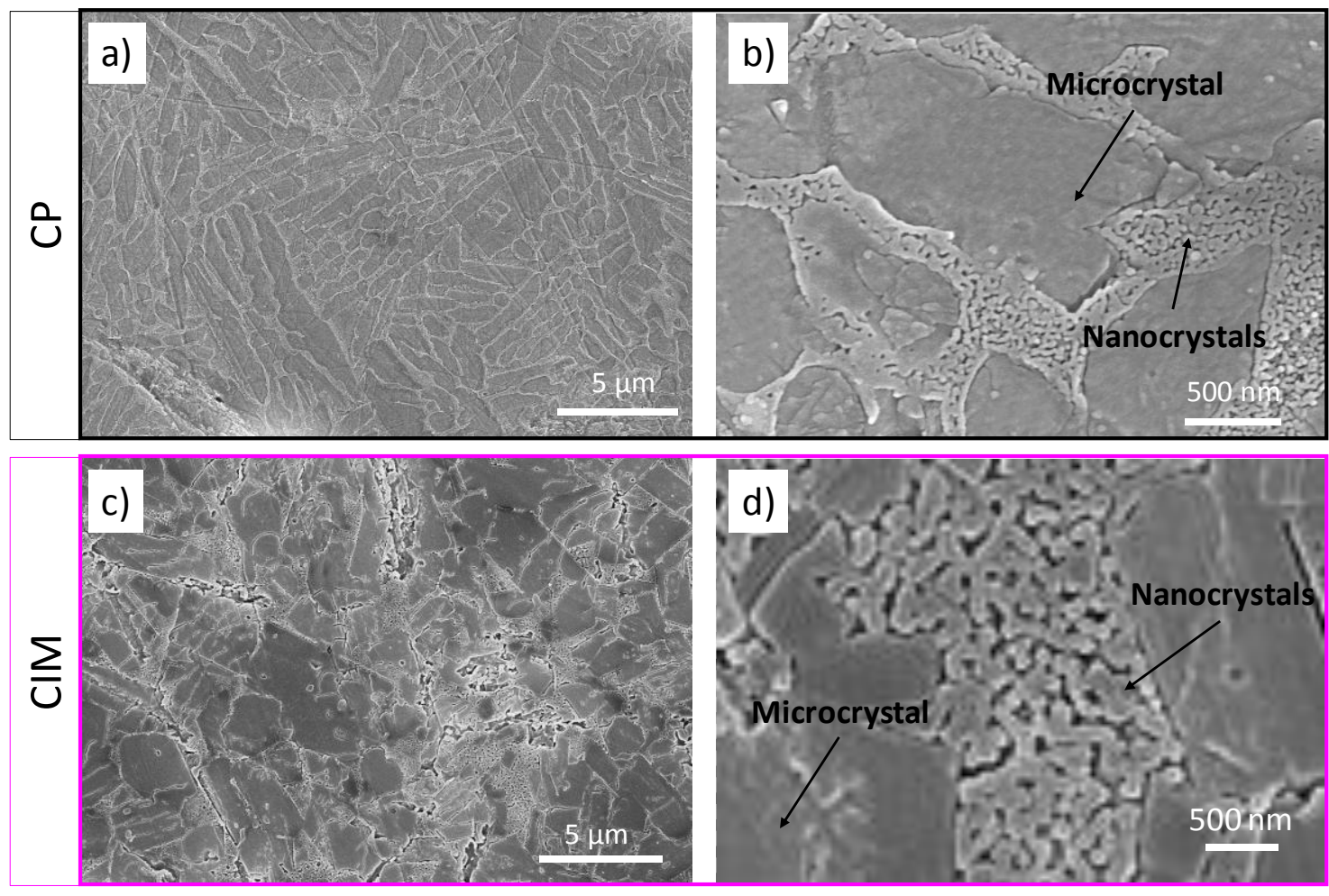

Figure 6: FESEM micrographs of a, b) CP and c, d) CIM samples.

These differences in the micro-nanostructures are strongly influenced by the CIM processes. Firstly, the precursor is thermally pre-treated at $700^{\circ} \mathrm{C}-1 \mathrm{~h}$ to remove the hydroxyl group of the kaolin. This thermally process does not induce devitrification of the amorphous precursor but modified the plasticity of the kaolin particles. Secondly, high shear stresses are applied to the feedstock during both the mix of the precursors and for the injection step. Theses stresses could produce the breakdown of the precursor amorphous particles, creating more nucleating seeds, from which the micro and nanocrystals will grow faster, increasing their sizes during the sintering. In addition, the binder removal during the debinding also produces a rearrangement of the material and the carbon residues could have influence, modifying the structure and microstructure of the material.

\subsection{Photoluminescent properties}

Figure 7 shows the photoluminescent (PL) emission of the two studied samples when they are excited with $\lambda_{\text {exc }}=322 \mathrm{~nm}$, which corresponds to the intrinsic luminescence due to structural defects [7]. In the CIM sample, a luminescent of one order of magnitude higher than a conventional ceramic is obtained. It is worth to remark that the luminescence is obtained without the presence of rare-earths. The deconvolution of the main emission band located at $340-450 \mathrm{~nm}$ 
was carried out for both samples by the second derivate method, in order to analyze the defect contribution in the PL emission (figures $7 \mathrm{~b}$ and $7 \mathrm{c}$ ). The deconvoluted peaks positions are summarized in table 2, with their associated defect. In addition, the ratio between the areas of each defect corresponding to the CP and the CIM samples was included in table 2, with the aim of comparing its contribution.

The first emission peak corresponds to the emission produced by quartz impurities. However, the blue luminescence is mainly produced by two kind of defects: the peaks attributed to [AlO4/alkali+] or $\left[\mathrm{AlO}_{4}\right]^{0}$ defects, where $\mathrm{Si}^{4+}$ ion is substituted by $\mathrm{Al}^{3+}$ and the local charge balance should be maintained by a positive charge. If this positive charge is an alkali cation placed in adjacent positions to $\mathrm{Al}^{3+}$ ions, the center formed will be $\left[\mathrm{AlO}_{4} / \mathrm{alkali}^{+}\right]$, while if a hole is trapped, the resulting centre will be an $\left[\mathrm{AlO}_{4}\right]^{0}[7,18,19]$; and the most common structural defect in feldspars, which corresponds to Al-O-Al centers (Löwenstein bridges) (400-480 nm) which occur when an oxygen hole center is adjacent to two $\mathrm{Al}^{3+}$ ions, one of them structural and the other one an impurity of $\mathrm{Al}$ [19-23]. The changes in the contribution of these defects can be observed by the areas ratio, which shows a trend of increasing defect population in the cases of the sample prepared from the feedstock, for $\left[\mathrm{AlO}_{4} / \mathrm{alkali}^{+}\right]$or $\left[\mathrm{AlO}_{4}\right]^{0}$ defects. However, the defects population associated to Al-O-Al centres decreases, especially for the band situated at $421 \mathrm{~nm}$. In addition, no significant wavelength shifts are observed in the emission peaks position for any defects. Therefore, the increase of almost one order of magnitude in the sample prepared from feedstock, is mainly due to the increase in the population of $\left[\mathrm{AlO}_{4} / \mathrm{alkali}^{+}\right]$or $\left[\mathrm{AlO}_{4}\right]^{0}$ defects. 

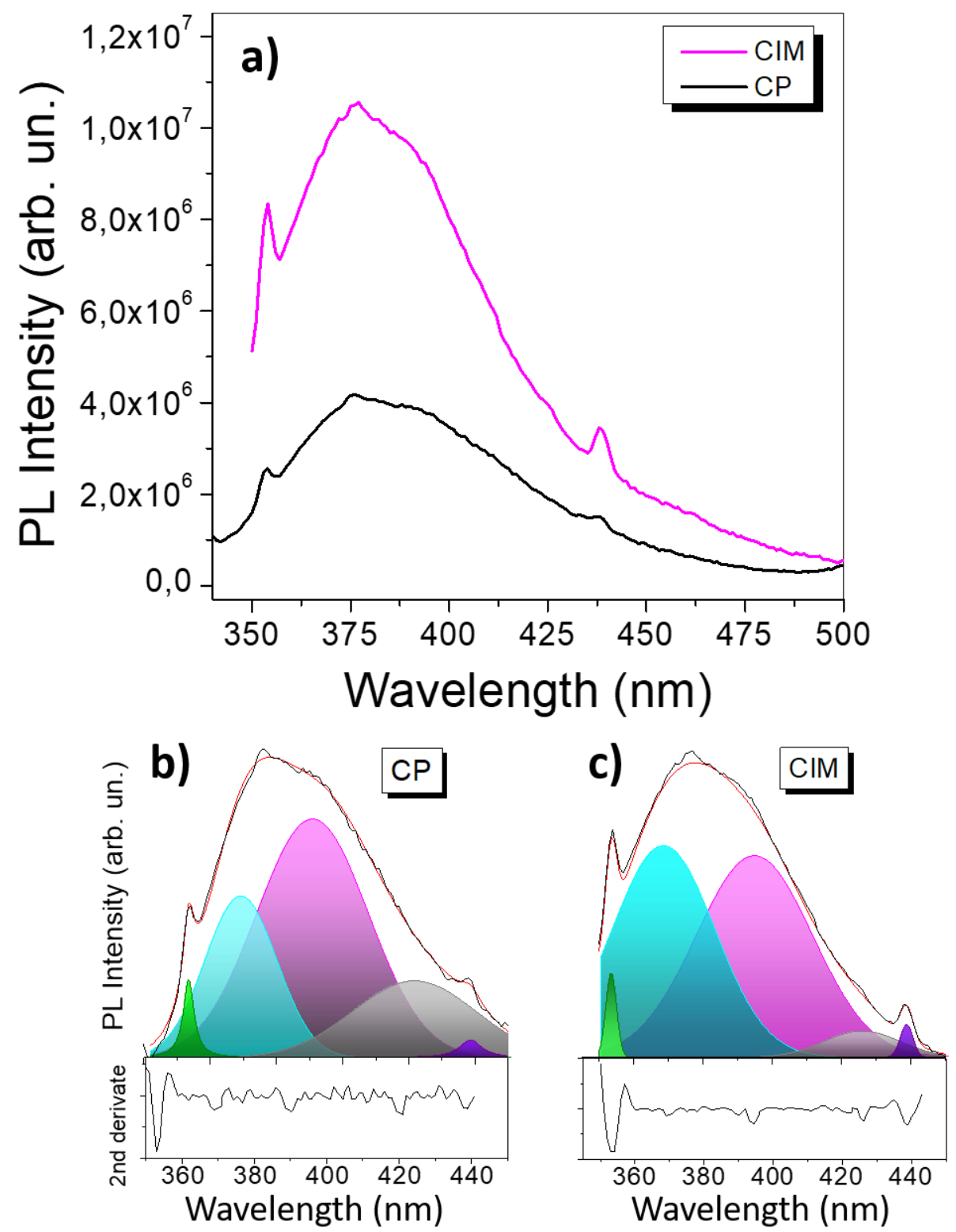

Figure 7: a) Photoluminescence emission of albite glass-ceramic material (CP sample) and the sample obtained by CIM, when they are excited with $\lambda_{\mathrm{exc}}=322 \mathrm{~nm}$, in the range of $300-650 \mathrm{~nm}$. b) and c) Deconvolution of the main peaks for the CP and the CIM samples obtained by the second derivate method, respectively, between $340-450 \mathrm{~nm}$, in order to obtain the defect contribution in the main emission of samples. b) and c) PL intensity y-axis is maximized for shake of clarity but correspond to different intensities as shown in a).

Defect

CP

CIM

$A_{C P} / A_{C I M}$

Quartz

353

354 0.7 
Table 2: Deconvoluted peaks position of the PL emission of the two studied samples and their defect association. Ratio of the areas of each defect peak regarding the CP sample.

Nevertheless, in order to analyse the influence of the structural distortions of the samples on the PL emission, Confocal Raman spectroscopy was carried out. Figure 8 shows the Raman spectra of the two samples (figure $8 a$ ) and the deconvolution of the main Raman peaks ( $v_{a}$ and $\left.v_{b}\right)$ situated at Raman shift between $450-540 \mathrm{~cm}^{-1}$ (figures $8 \mathrm{~b}$ and $8 \mathrm{c}$ ), also obtained by the second derivate method, as seen in each figure. Raman modes located below $200 \mathrm{~cm}^{-1}$ are attributed to the cageshear modes and, between $200-400 \mathrm{~cm}^{-1}$, it appears the rings rotation - translation modes. The main Raman peaks located between $450-540 \mathrm{~cm}^{-1}$ correspond to the breathing modes of the four membered tetrahedral rings of the albite structure [24] and they are enlargement in the inset of figure 8a. The deformation modes are represented between $600-900$ $\mathrm{cm}^{-1}$ and, finally, the vibrational stretching modes of the feldspar are located between 900-1200 $\mathrm{cm}^{-1}$.

The main Raman peaks are observed at $480 \mathrm{~cm}^{-1}\left(\mathrm{vb}_{\mathrm{b}}\right)$ and $511 \mathrm{~cm}^{-1}\left(\mathrm{Ua}_{\mathrm{a}}\right)$ and they indicate that the $\mathrm{Si}-\mathrm{O}-\mathrm{Si}$ and $\mathrm{Si}-\mathrm{O}-\mathrm{Al}$ bond angles are distributed in two groups. $v_{\mathrm{b}}$ is mainly assigned to tetrahedral ring compression-expansion within the ab plane, and $v_{a}$ to a compression-expansion of four-membered ring along $c$, and they also contribute to the translation of $\mathrm{Na}$ along $a b$ plane and a-axis, respectively $[17,25-27]$.

The position of the four deconvoluted Raman peaks are presented in table 3, additionally to the Full Width at Half Maximum (FWHM) of $v_{b}$, named $\Delta \Gamma_{b}$ which provide information about the order/disorder of Si/Al, in such a way that an increase in $\Delta \Gamma_{b}$ supposes an increase of the Si/Al disorder. 
All the Raman peaks of the CIM sample undergo a blue Raman shift, except for the mode 2, that undergoes a Raman red shift. This trend indicates larger lattice compression in the CIM sample, probably due to the process conditions, such as high shear stress and the presence of carbon during the thermal treatment, which tend to increase the crystallinity and the particle size of the feldspar, as seen before. All these factors favor a larger compression of the bonds which is more evident in the $\boldsymbol{c}$ plane $\left(\mathrm{U}_{\mathrm{a}}\right)$.

Raman modes signaled as 1 and 2, located at ca. $462.7 \mathrm{~cm}^{-1}$ and ca. $532.8 \mathrm{~cm}^{-1}$ respectively, in the ceramic process sample, describe (Si,Al) tetrahedral deformation. In the first one, Si-cations contribute to the motion, particularly in the T2(0) tetrahedral [3228]. In the second one, the deformation is along the $\mathrm{Na}-\mathrm{O}$ stretching [29]. Raman modes 1 and 2 increase in the CIM sample, especially the Raman mode 2, which indicates that the deformation in the $\mathrm{Na}-\mathrm{O}$ stretching is larger when the sample is processed by this method.
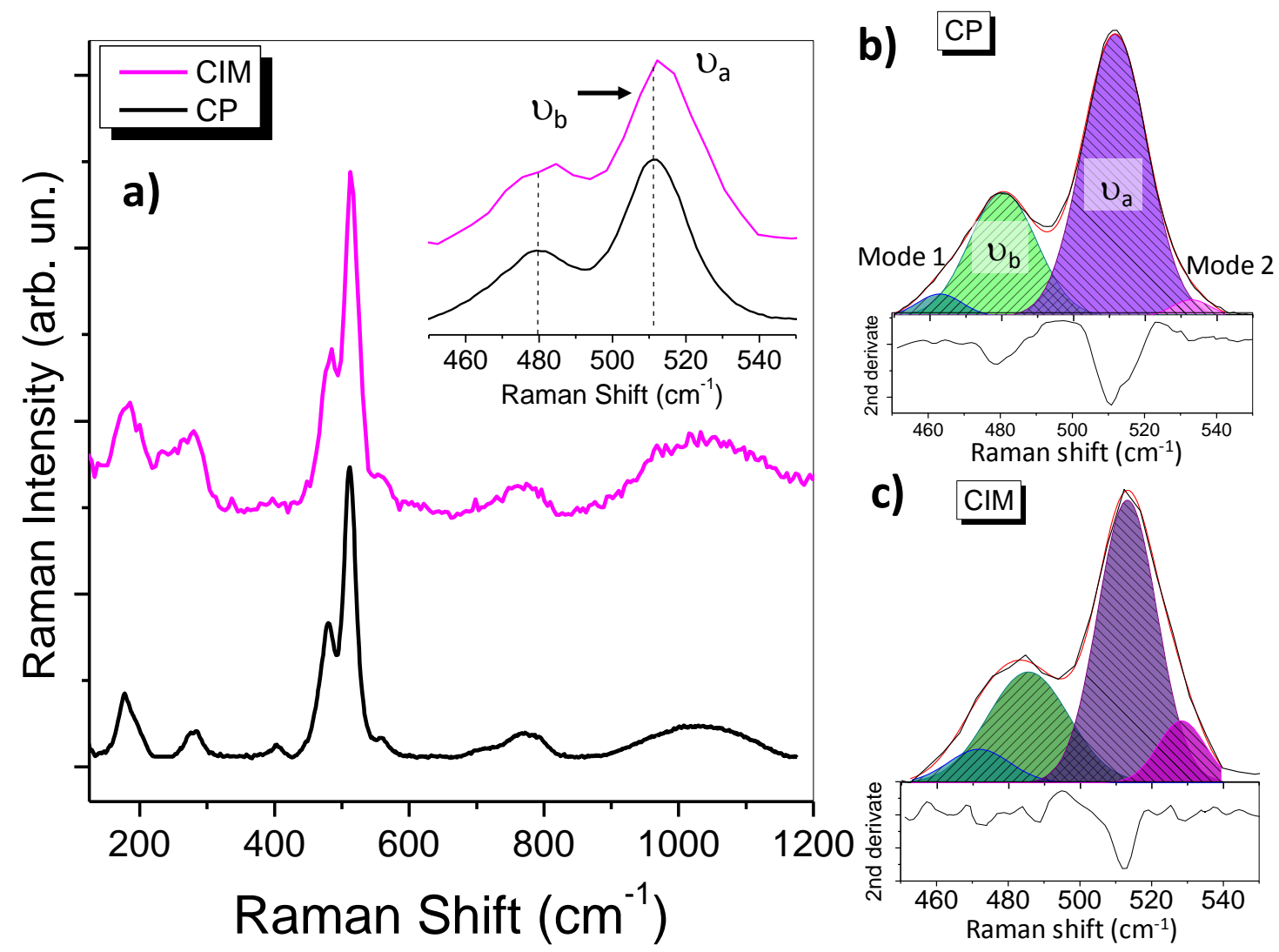

Figure 8. a) Raman spectra of the two samples; b, c) Raman spectrum deconvolution of both sample, showing four Raman modes determined by the second derivate method.
Sample
Ua
Ub
Mode $1 \quad$ Mode 2
$\Delta \Gamma_{\mathrm{b}}$ 
Table 3: Raman shift of the four deconvoluted peaks, the FWHM of the $v_{b}$ mode $\left(\Delta \Gamma_{b}\right)$ and the difference between the $v_{a}$ and $v_{b}$ modes position for the samples obtained by the ceramic process $(\mathrm{CP})$ and the ceramic injection molding (CIM).

Modes $v_{a}$ and $v_{b}$ are influenced by the composition and Si/Al order/disorder changes. Both Raman modes undergo a blue-shift that is more pronounced for the $v_{a}$ mode. The FWHM of $v_{b}$ mode $\left(\Delta \Gamma_{\mathrm{b}}\right)$ indicates the order/disorder degree of feldspars at microscopic scale [27], so that an increase in this parameter indicates greater disorder and a decrease indicates a larger order because more $\mathrm{Al}^{3+}$ cations are placed in positions $\mathrm{T} 1(0)$, avoiding the formation of luminescent centers [9]. As it is tabulated in table 3 , the $\Delta \Gamma_{\mathrm{b}}$ in CIM sample increases, indicating larger defects formation in this kind of process, which justify the increase of almost one order of magnitude of photoluminescence.

\section{Conclusions}

A dense ceramic based on Na-rich feldspar has been successfully obtained by ceramic injection molding (CIM) reaching the same composition and higher crystallinity than the one obtained by the conventional ceramic process (CP). A significant high glass-ceramic content in the $\mathrm{CIM}$ feedstock has been developed (70 vol.\%) which leads to high quality and highly densified sintered parts. The microstructure of the sample prepared by CIM revealed changes presenting larger particles size and larger nanoparticles regions. These changes are probably due to the high shear stress produced in the sample during the mixing process or/and by the carbon residues after polymer debinding. Both processes could produce local changes in the environment during the sintering step that resulted in modification of the devitrification processes. Contrary to what might be expected, the optical functional properties of the material obtained by this method is not only not degraded but improved. Photoluminescence increases almost one order of magnitude when a ceramic piece is obtained by CIM process in comparison with the ceramic process, due to the increase of $\left[\mathrm{AlO}_{4} / \mathrm{alkali}^{+}\right]$or $\left[\mathrm{AlO}_{4}\right]^{0}$ defects population. This increase is corroborated by Raman spectroscopy where the mode corresponding to the breathing modes 
of the four membered tetrahedral rings of the albite structure (ub), that indicates the Si/Al order/disorder, undergoes a widening, indicating a greater disorder of the feldspar structure. In addition, a lattice compression is produced due to the process conditions that, not only modifies the microstructure, but also the crystallinity and ordination of the structure. Therefore, the CIM procedure provide an advantageous method to obtain dense functional ceramic with great versatility of shapes and dimensions, that can even improve the optical properties of feldspar glass-ceramics, opening new fields of applications.

\section{Acknowledgments}

The authors express their thanks to the MINECO project MAT2017-86450-C4-1-R, and project CDTI of CTV for their financial support. In addition, authors thanks to Vidres S. A. for the raw materials provided. The authors gratefully acknowledge the financial support by JCCM (Junta de Castilla La Mancha) in the Regional Funding Programme for Scientific Research (SBPLY/17/180501/000550).

\section{References}

[1] P. Ramakrishnan, Structural Ceramics, Key Eng. Mater. 29-31 (2009) 839-0. doi:10.4028/www.scientific.net/kem.29-31.839.

[2] B.C. Mutsuddy, R.G. Ford, Ceramic Injection Moulding, Chapman \& Hall, UK, 1995.

[3] R.M. German, A. Bose, Injection Molding of Metals and Ceramics, Metal Powder Industries Federation, USA, 1997.

[4] M. Narisawa, H. Kado, R. Mori, M. Yoshida, H. Mabuchi, Influence of network structure on abnormally high viscosity of mixed slurries of silicon carbide nanopowder and polycarbosilane, J. Ceram. Soc. Japan. 115 (2007) 982-986.

[5] P. Colombo, E. Bernardo, G. Parcianello, Multifunctional advanced ceramics from preceramic polymers and nano-sized active fillers, J. Eur. Ceram. Soc. 33 (2013) 453469. doi:10.1016/j.jeurceramsoc.2012.10.006.

[6] N. Williams, PIM International, 12 (March 2018) 1-108.

[7] V. Fuertes, J.F. Fernández, E. Enríquez, Enhanced luminescence in rare-earth-free fastsintering glass-ceramic, Optica. 6 (2019) 668. doi:10.1364/optica.6.000668.

[8] V. Fuertes, J.F. Fernández, E. Enríquez, Tunable UV/blue luminescence in rare-earth free 
glass-ceramic phosphor, J. Eur. Ceram. Soc. 39 (2019) 3221-3228. doi:10.1016/j.jeurceramsoc.2019.04.027.

[9] A. Putnis, "The crystal structure of minerals II-silicates" in An Introduction to Mineral Sciences , pp. 141-184, Cambridge University Press, 1992, 1992.

[10] M. Pagel, V.Barbin, P. Blanc, D. Ohnenstetter, Cathodoluminescence in geosciences, Springer-Verlag Berlin Heidelberg, New York, 2000. doi:10.1007/978-3-642-56680-6.

[11] E. Enríquez, V. Fuertes, M.J. Cabrera, J. Seores, D. Muñoz, B. Galiana, J.F. Fernández, Study of the crystallization in fast sintered Na-rich plagioclase glass-ceramic, Ceram. Int. (2019) 0-1. doi:10.1016/j.ceramint.2019.01.219.

[12] V. Fuertes de la Llave, A. del Campo, J.F. Fernández, E. Enríquez, Structural insights of hierarchically engineered feldspars by confocal Raman microscopy, J. Raman Spectrosc. 50 (2019) 741-754. doi:10.1002/jrs.5556.

[13] G. Herranz, B. Levenfeld, A. Várez, J. M. Torralba, Development of new feedstock formulation based on high density polyethylene for MIM of M2 high speed steels, Powder Metallurgy, 48, 2 (2005) 134-138. doi:10.1179/003258905X37828.

[14] BZ. Rabinowitsch. Physika Chemistry (1929) 145A:1.

[15] T. S. Shivashankar; R. K. Enneti, S.J. Park; R. M. German; S. Atre. (2013): The effects of material attributes on powder-binder separation phenomena in powder injection molding. En: Powder Technology 243, pág. 79-84. DOI:10.1016/j.powtec.2013.03.037.

[16] N. Casson. (1959): Rheology of disperse systems: Pergamon Press.

[17] J. Janardhana,; N. Ravi, M. Vijayakumar. "A simple model for viscosity of powder injection moulding mixes with binder content above powder critical binder volumen concentration". Journal of the European Ceramic Society, vol. 20, pp. 2183-2190, 2000

[18] J. Garcia-Guinea, P.D. Townsend, L. Sanchez-Munoz, J.M. Rojo, Ultraviolet-blue ionic luminescence of alkali feldspars from bulk and interfaces, Phys. Chem. Miner. 26 (1999) 658-667. doi:10.1007/s002690050231.

[19] V. Correcher, J. Garcia-Guinea, L. Sanchez-Muñoz, T. Rivera, Luminescence characterization of a sodium-rich feldspar, Radiat. Eff. Defects Solids. 162 (2007) 709714. doi:10.1080/10420150701482063. 
[20] S. Maki, S. Ohgo, H. Nishido, Cathodoluminescence characterization of feldspar minerals from granite-syenite rocks in Iwagijima Island, Ehime Prefecture, Japan, Naturalistae. 18 (2016) 13-18.

[21] M. Kayama, S. Nakano, H. Nishido, Characteristics of emission centers in alkali feldspar: A new approach by using cathodoluminescence spectral deconvolution, Am. Mineral. 95 (2010) 1783-1795. doi:10.2138/am.2010.3427.

[22] D.J. Huntley, D.I. Godfrey-Smith, E.H. Haskell, Light-induced emission spectra from some quartz and feldspars, Int. J. Radiat. Appl. Instrumentation. Part. 18 (1991) 127-131. doi:10.1016/1359-0189(91)90104-P.

[23] M.L. Clarke, H.M. Rendell, Infra-red stimulated luminescence spectra of alkali feldspars, Radiat. Meas. 27 (1997) 221-236. doi:10.1016/S1350-4487(96)00139-4.

[24] J.J. Freeman, John J. Alian Wang, K.E. Kuebler, L.A. Haskin, Characterization of natural feldspar by Raman spectroscopy for future planetary exploration, Can. Mineral. 46 (2008) 1477-1500. doi:10.3749/canmin.46.6.1477.

[25] I. Aliatis, E. Lambruschi, L. Mantovani, D. Bersani, S. Andò, G. Diego Gatta, P. Gentile, E. Salvioli-Mariani, M. Prencipe, M. Tribaudino, P.P. Lottici, A comparison between ab initio calculated and measured Raman spectrum of triclinic albite $($ NaAlSi $<$ inf $>3<$ inf $>0<$ inf $>8</$ inf $>$ ), J. Raman Spectrosc. $46 \quad$ (2015) 501-508. doi:10.1002/jrs.4670.

[26] D. Bersani, C. Conti, P. Matousek, F. Pozzi, P. Vandenabeele, Methodological evolutions of Raman spectroscopy in art and archaeology, Anal. Methods. 8 (2016) 8395-8409. doi:10.1039/c6ay02327d.

[27] D. Bersani, I. Aliatis, M. Tribaudino, L. Mantovani, A. Benisek, M.A. Carpenter, G.D. Gatta, P.P. Lottici, Plagioclase composition by Raman spectroscopy, J. Raman Spectrosc. (2018) 1-15. doi:10.1002/jrs.5340.

[28] I. Aliatis, E. Lambruschi, L. Mantovani, D. Bersani, S. Andó, G. Diego Gatta, P. Gentile, E. Salvioli-Mariani, M. Prencipe, M. Tribaudino, P.P. Lottici, A comparison between ab initio calculated and measured Raman spectrum of triclinic albite (NaAlSi3O8), J. Raman Spectrosc. 46 (2015) 501-508. doi:10.1002/jrs.4670.

[29] D.A. McKeown, Raman spectroscopy and vibrational analyses of albite: From $25^{\circ} \mathrm{C}$ 
through the melting temperature, Am. Miner. 90 (2005) 1506-1517. doi:10.2138/am.2005.1726. 

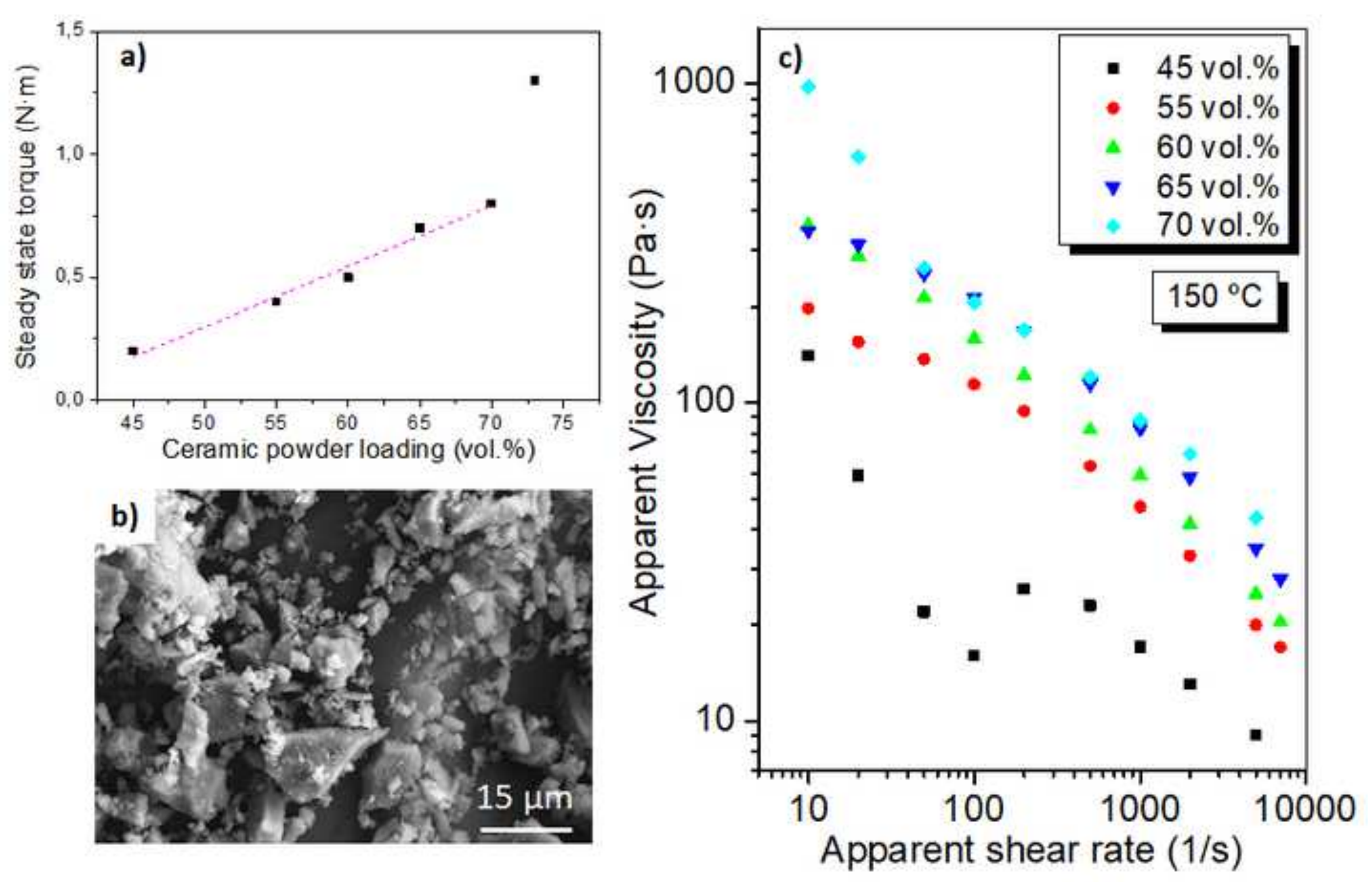
Figure

Click here to download high resolution image

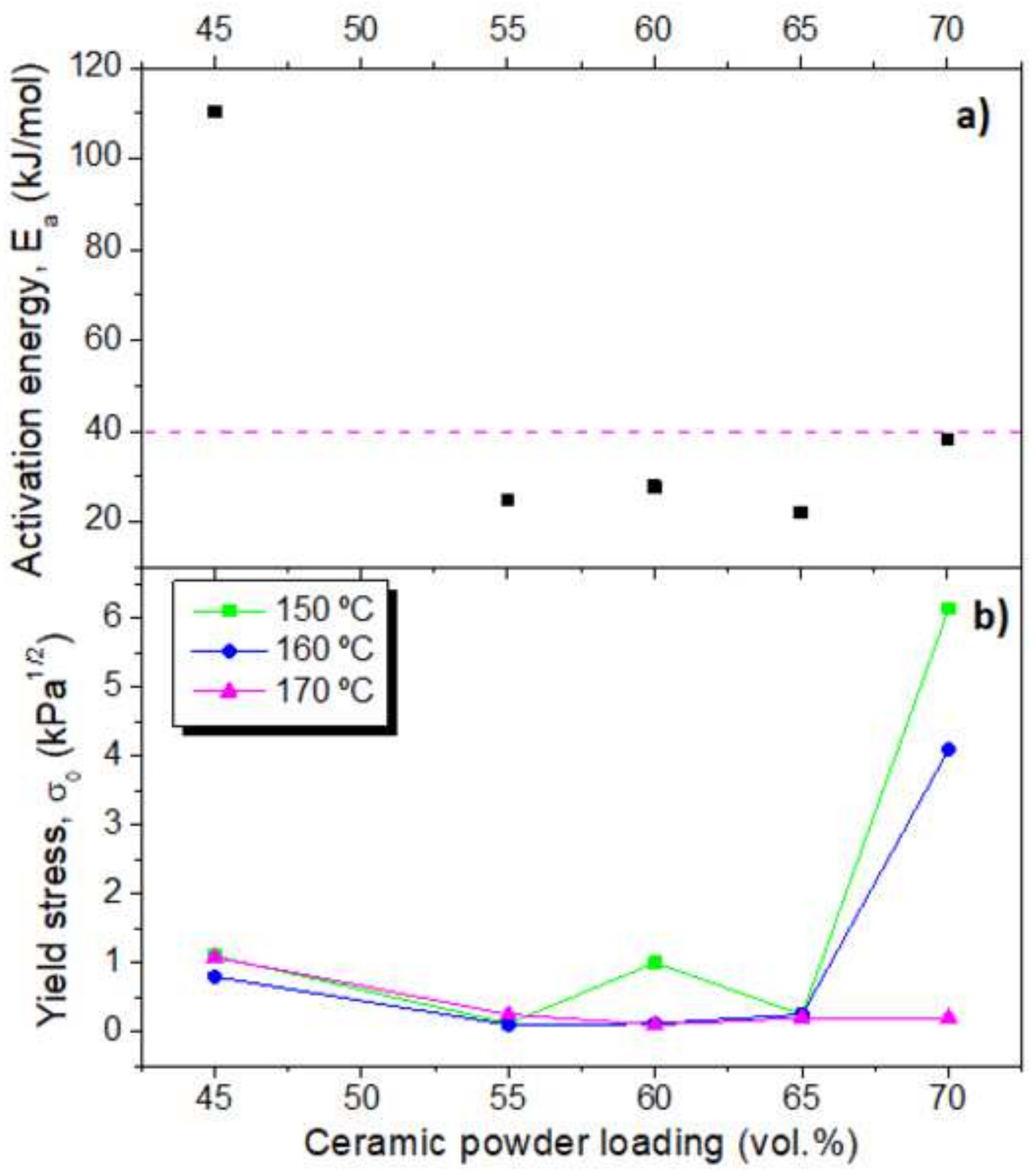



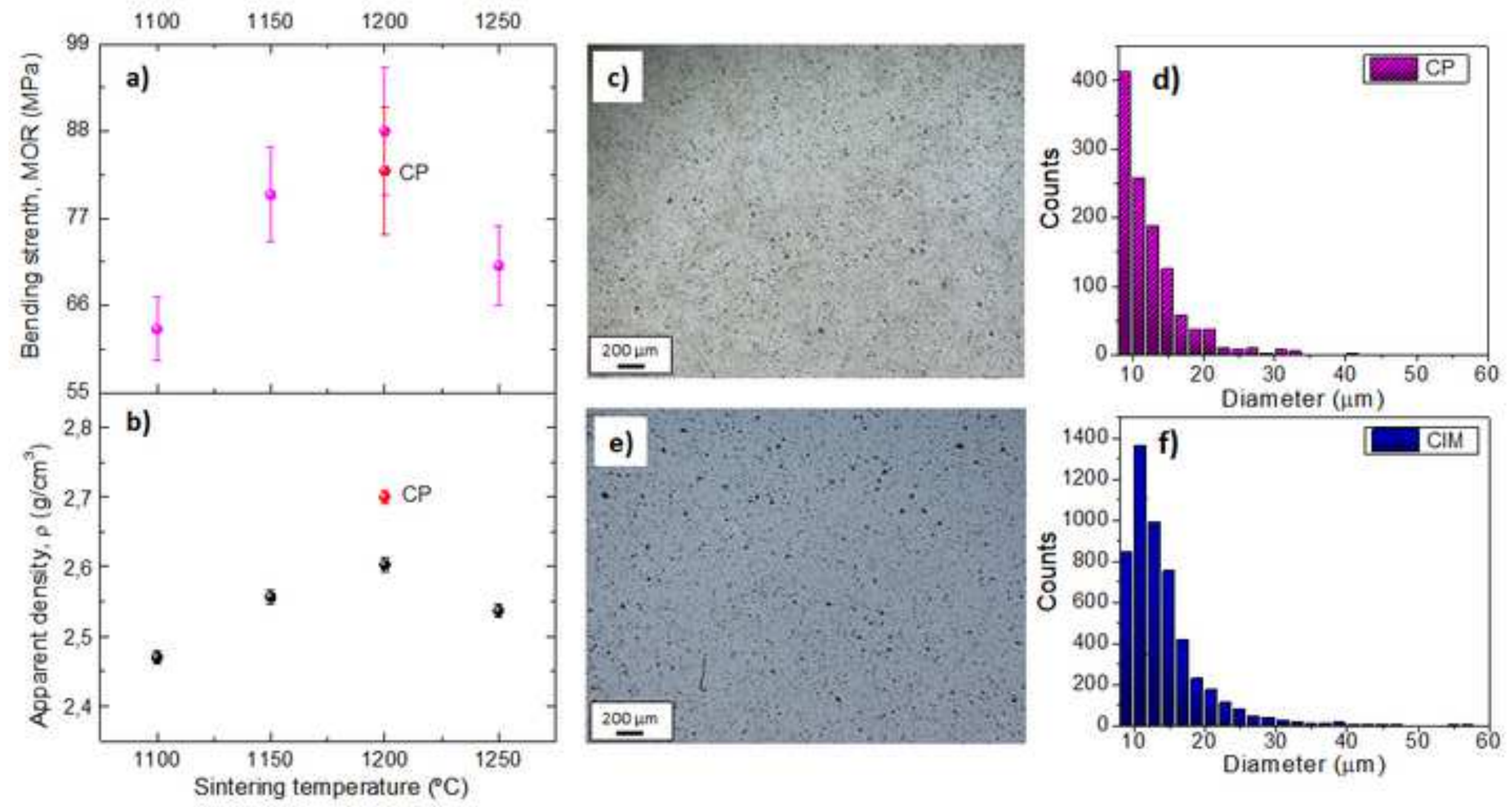


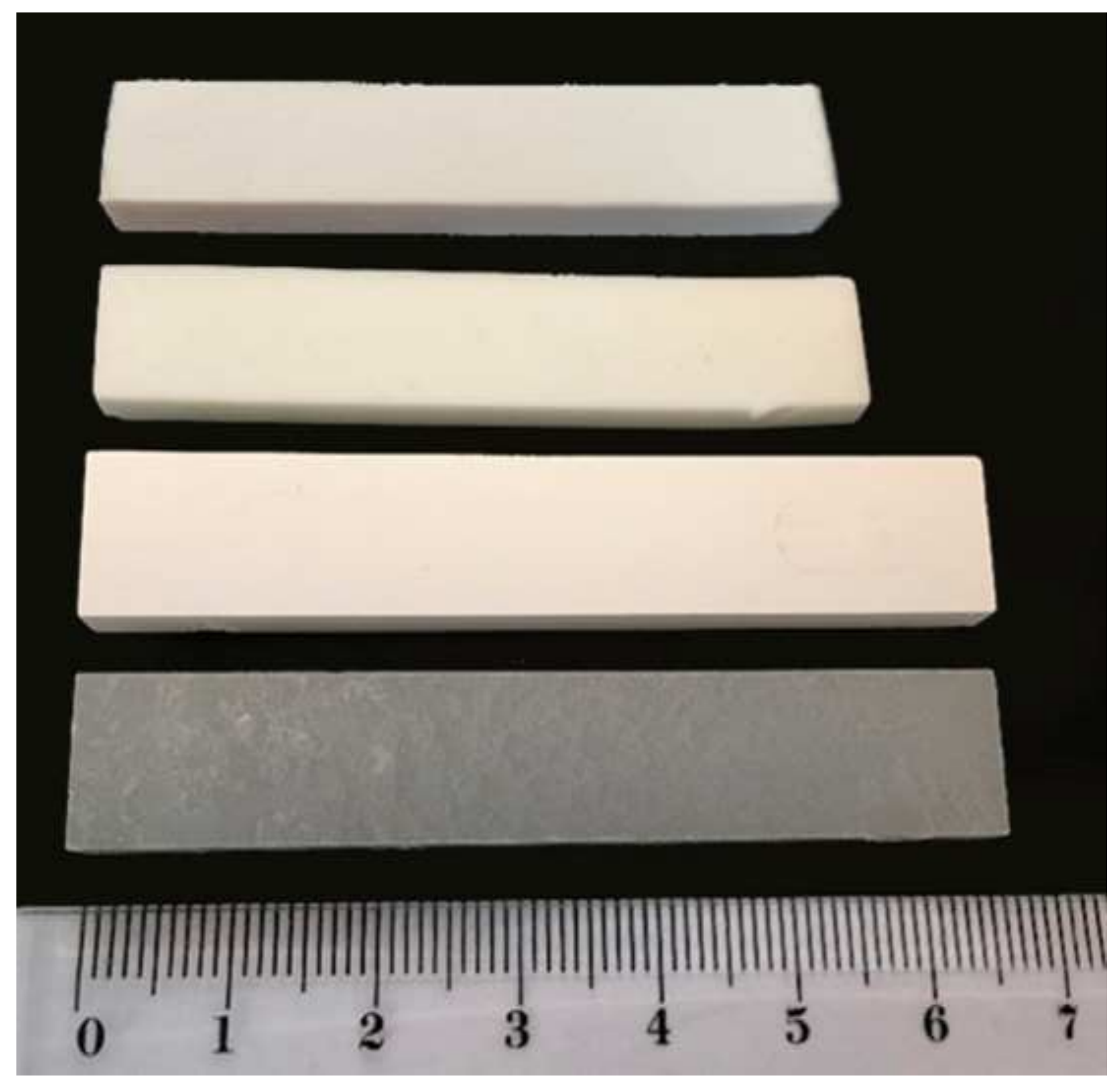




\section{Figure}

Click here to download high resolution image

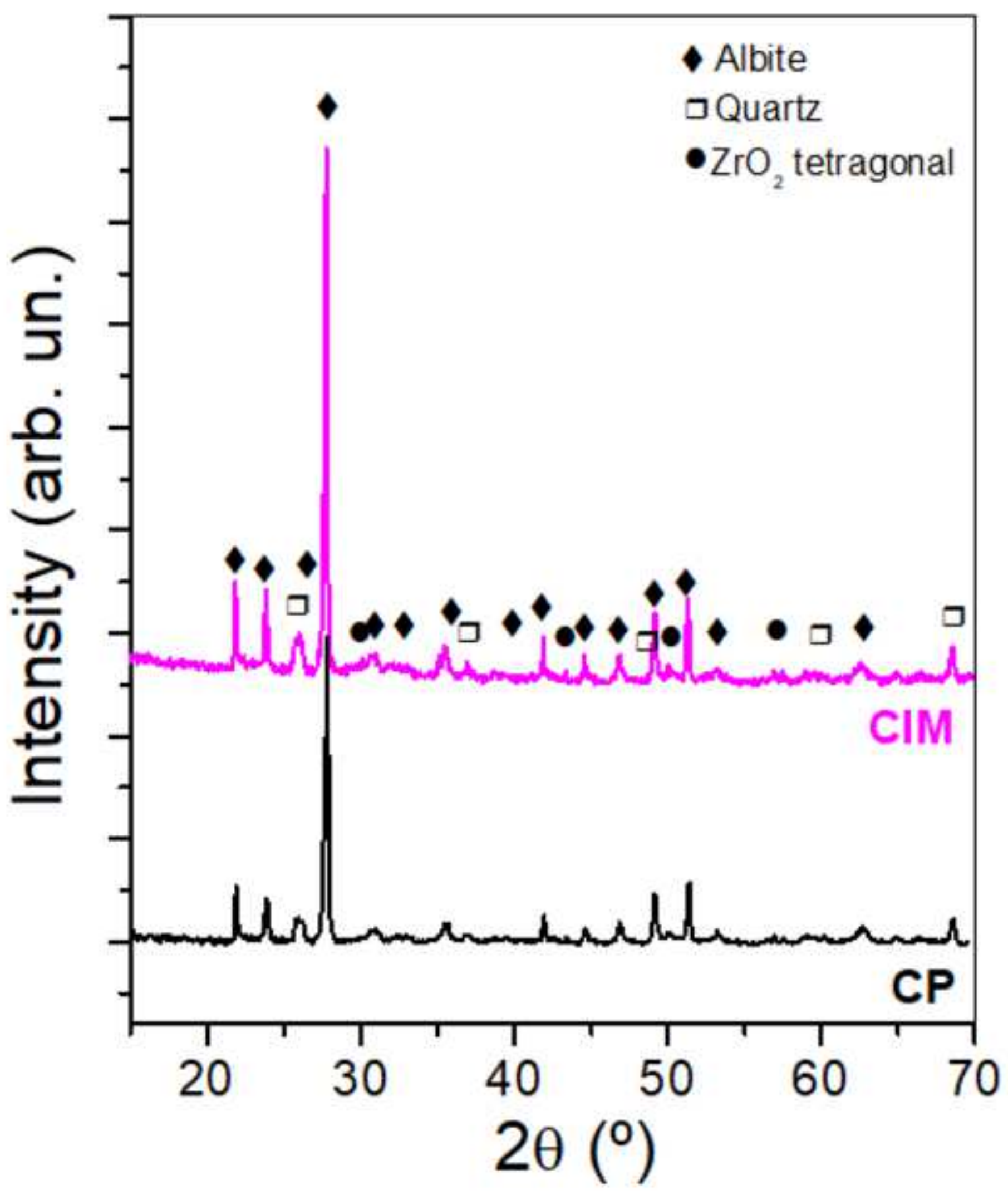



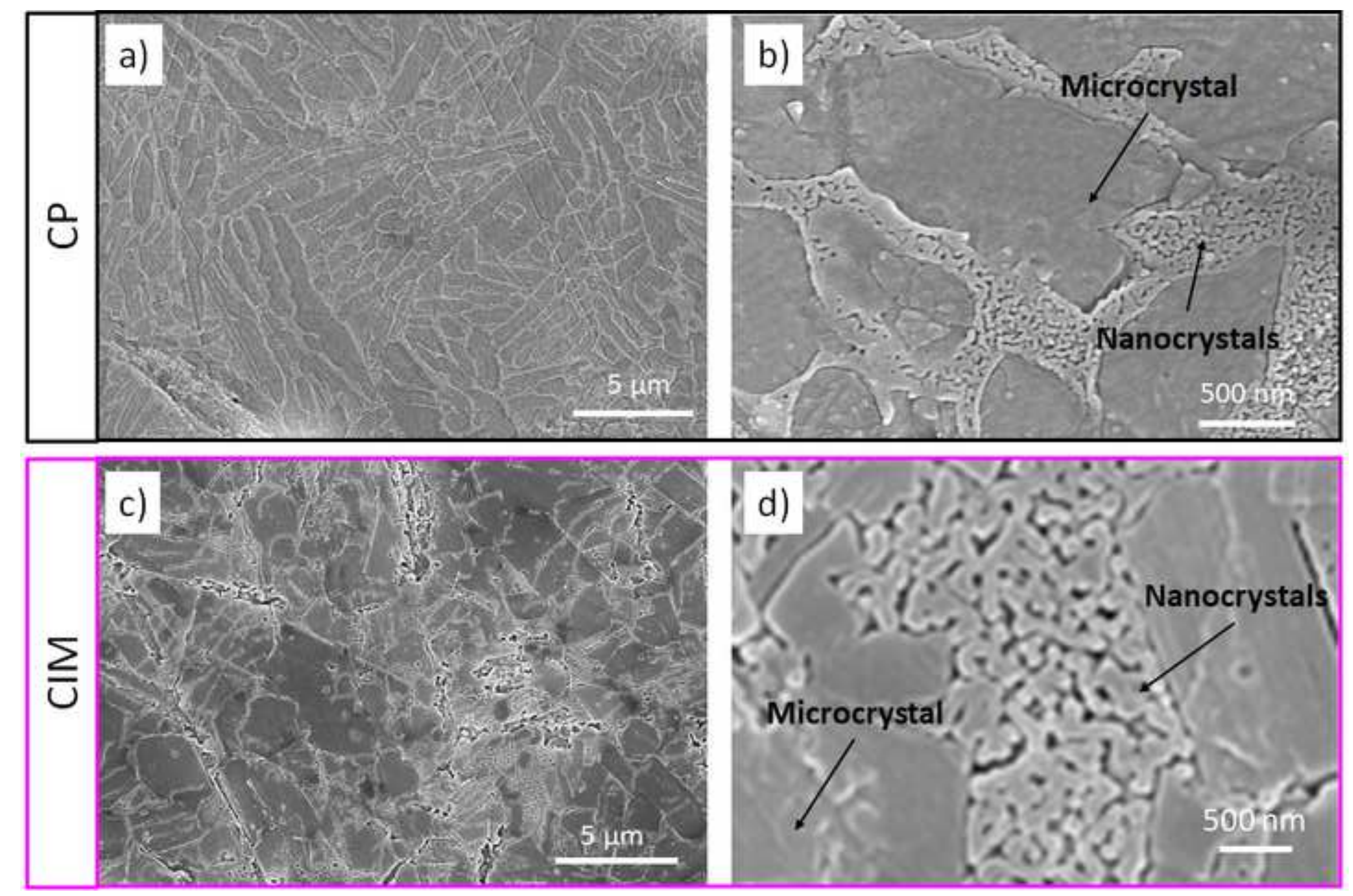

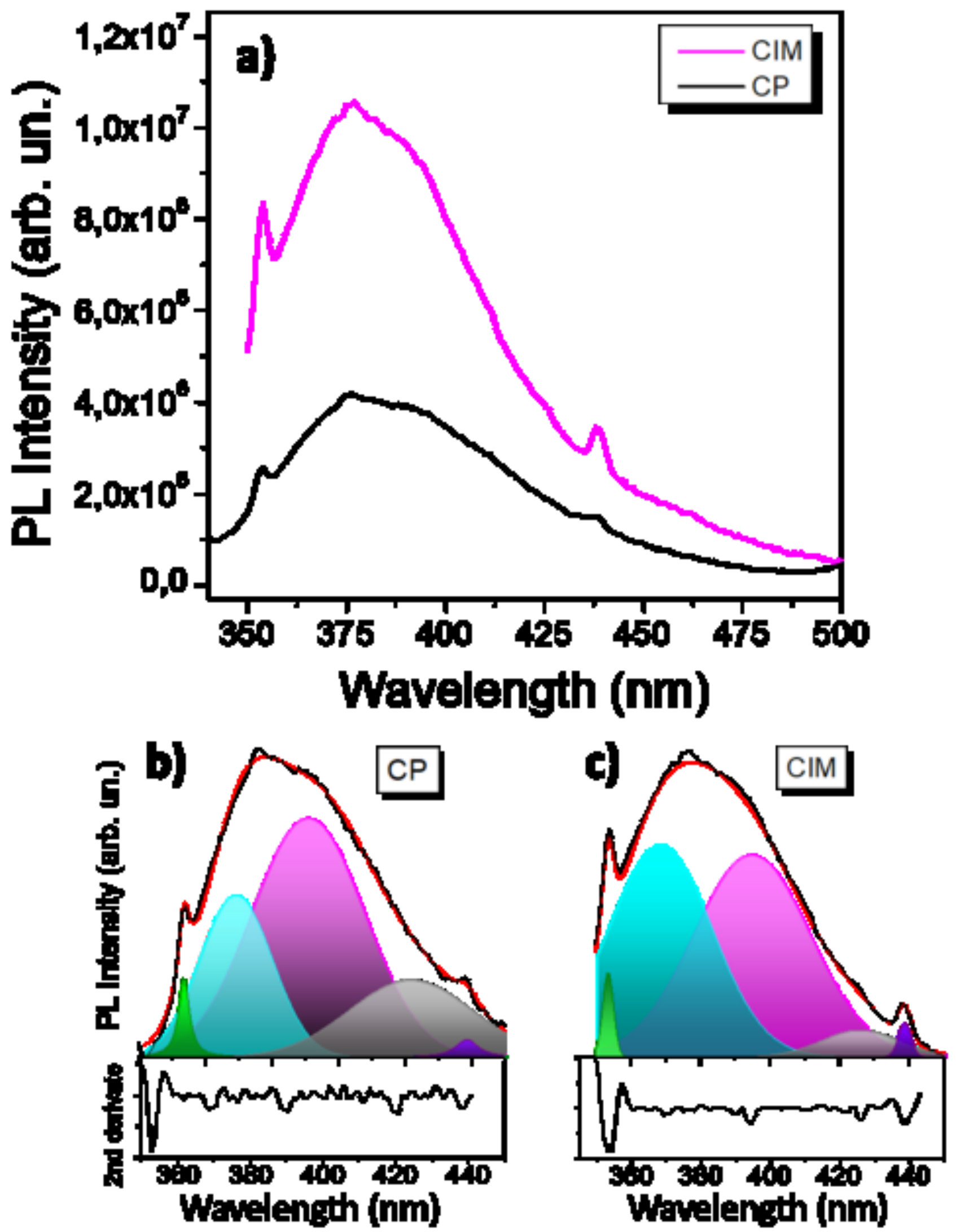

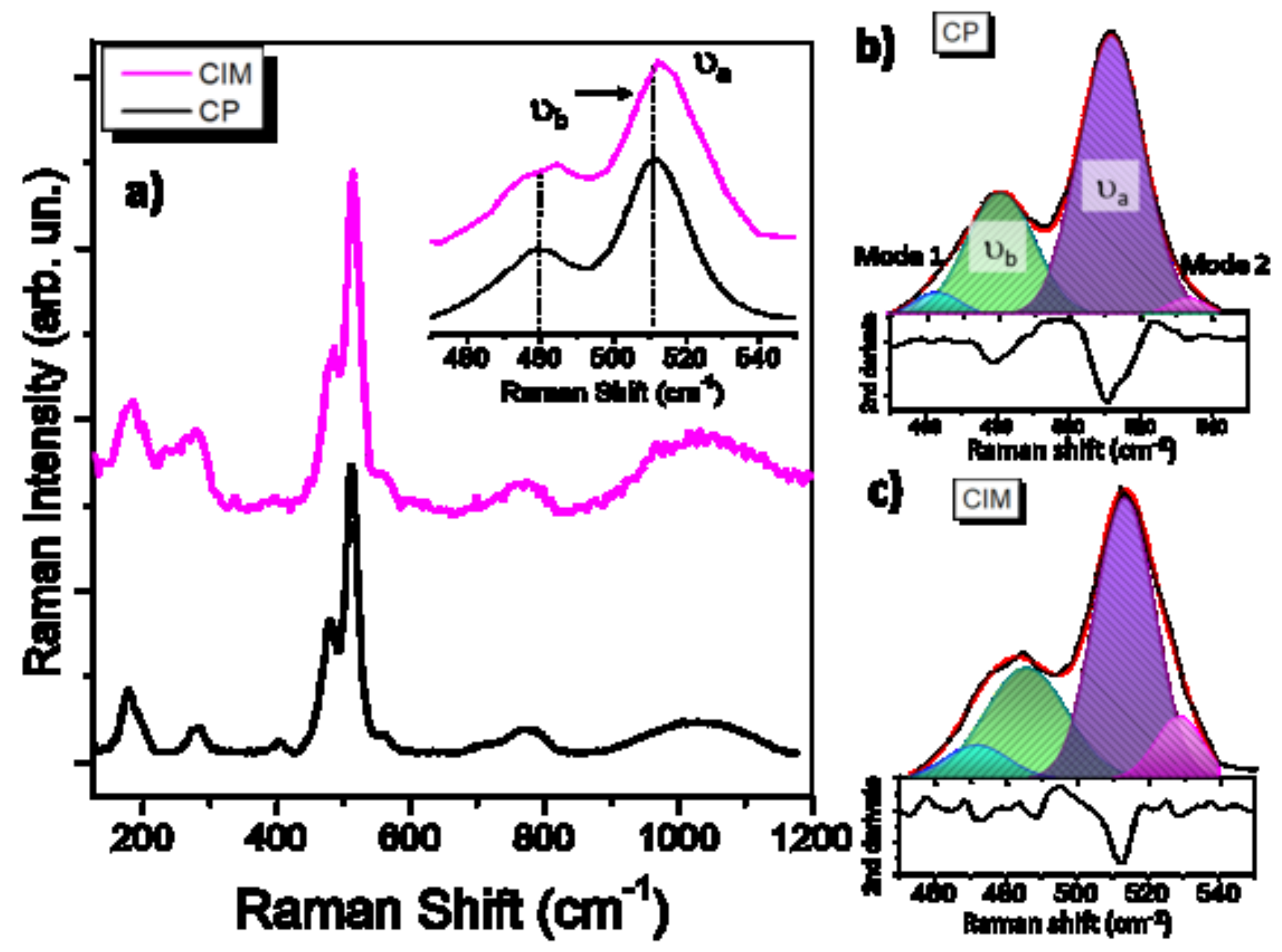
e-component
Click here to download e-component: supporting information.docx

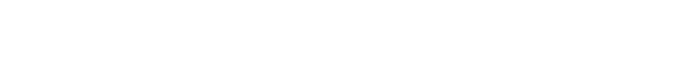

docx

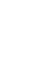
(1) (1) (1)

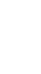
(1)

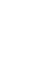
(1) (1)

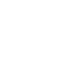

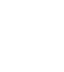

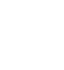
. . . . . . . . . . 